doi:10.12662/2359-618xregea.v9i2.p48-59.2020

ARTIGOS

\title{
ANÁLISE DA EFICIÊNCIA RELATIVA DOS GAS- TOS ESTADUAIS EM SEGURANÇA PÚBLICA
}

\section{ANALYSIS OF THE RELATIVE EFFICIENCY OF STATE EXPENSES IN PUBLIC SECURITY}

\section{RESUMO}

A presente pesquisa tem por objetivo analisar a eficiência dos gastos em segurança efetivados pelos estados brasileiros e Distrito Federal no exercício 2017. Para tanto, foi utilizada a metodologia Análise Envoltória de Dados - DEA, orientada a resultados e com retornos variáveis de escala. Os resultados evidenciaram um nível baixo de eficiência, com valor médio de $65,6 \%$, sendo apenas sete estados considerados eficientes. Além disso, restou demonstrada a associação negativa entre desempenho e aumento do investimento público. Das unidades eficientes, Paraíba, Rio Grande do Norte e São Paulo tiveram retornos constantes de escala, significando que estão laborando sem desperdícios. Quanto aos benchmarcks, São Paulo foi indicado como referência para todas as 20 DMU's ineficientes. Conclui-se, portanto, que os estados brasileiros possuem, em regra, um considerável potencial de melhoria de resultados, sendo relevante repensar a alocação dos recursos disponíveis, inclusive, por meio da observação de práticas adotadas pelos benchmarcks respectivos.

Palavras-chave: Políticas públicas. Segurança pública. Eficiência. DEA.

Meiry Mesquita Monte meirymesquita@yahoo.com.br Mestra em Administração e Controladoria pela Universidade Federal do Ceará. Fortaleza-CE-BR.

Cláudio Bezerra Leopoldino claudio.leopoldino@ufc.br Doutor em Administração pela Universidade Federal da Bahia. Professor do Departamento de Administração da Universidade Federal do Ceará. Fortaleza$C E-B R$.

\section{ABSTRACT}

The present research has the objective of analyzing the efficiency of security expenditures by the Brazilian states and the Federal District in the 2017 fiscal year. For this purpose, the Data Envelopment Analysis (DEA) methodology was applied, oriented to results and with variable returns of scale. The results showed a low level of efficiency, with an average value of $65.6 \%$, with only seven states being considered efficient. In addition, there was a negative association between performance and increased public investment. Of the efficient units, Paraíba, Rio Grande do Norte and São Paulo had constant returns of scale, meaning that they are working without waste. As for the benchmarking, São Paulo 
was indicated as a reference for all 20 inefficient DMUs. It is concluded, therefore, that the Brazilian states have, as a rule, a considerable potential for improvement of results, and it is relevant to rethink the allocation of available resources, including by observing practices adopted by the respective benchmarcks.

Keywords: Public Policies. Public Security. Efficiency. DEA.

\section{INTRODUÇÃO}

Segundo o Atlas da Violência 2018, em um período de 10 anos (de 2007 a 2016), foram contabilizados, no Brasil, mais de 493 mil homicídios, quantitativo que corresponde, por exemplo, à população do município de Florianópolis (SC). Os números da violência no Brasil alcançam dimensões ainda mais expressivas quando comparados a guerras internacionais deste século. O conflito sírio, por exemplo, foi iniciado em 2011 e conta com algo em torno de 500 mil mortos (CERQUEIRA et al., 2018; IBGE, 2018; OSDH, 2018).

Ao lado dos números de homicídios, coadjuvam índices de vários outros atentados aos indivíduos e ao patrimônio, como roubos, lesões corporais e violências sexuais. Tal cenário tem feito que a questão da segurança pública venha avançando, paulatinamente, na agenda política nacional, assumindo uma posição de destaque, tanto para a população, quanto para os gestores públicos (ERVILHA; LIMA, 2019; SANTOS; GONTIJO; AMARAL, 2015).

Salienta-se, ainda, que a Constituição Federal define que segurança pública é dever do Estado, direito e responsabilidade de todos, devendo ser exercida de modo a garantir a preservação da ordem pública e da incolumidade das pessoas e do patrimônio (BRASIL, 1988). No caso brasileiro, especificamente, a gestão da segurança pública é uma das poucas atribuições delegadas exclusivamente aos estados (GONÇALVES; SIQUEIRA, 2019; AFONSO, 2017).

Dada a sensibilidade do tema, é relevante questionar se os Estados brasileiros e o Dis- trito Federal estão sendo eficientes em relação a seus gastos com segurança pública, de modo que os insumos dirigidos a tais dispêndios tenham melhor aproveitamento, gerando a consequente maximização de resultados positivos.

Tal necessidade ganha especial relevo diante da crise econômica experimentada pelo país nos últimos anos, atingindo o setor privado e o governo em suas esferas federal, estadual e municipal. O desequilíbrio das finanças do governo federal resultou na aprovação da emenda constitucional que impôs um teto de gastos por 20 anos, além da redução da atividade econômica e dos repasses de recursos aos estados (BRASIL, 2016). A necessidade de gestão eficiente dos gastos com segurança aumenta à medida que os recursos escasseiam e passam a ser disputados nas áreas como saúde, educação e no pagamento de compromissos diversos (LIMA; MACIEL, 2018; NORONHA et al., 2018).

Nessa ordem de ideias, e partindo da perspectiva da relevância das políticas públicas de segurança para o bem-estar da população, o presente trabalho objetiva, por meio da metodologia Análise Envoltória de Dados (Data Envelopment Analysis) - DEA, avaliar a eficiência dos gastos em segurança pública que foram realizados pelos estados brasileiros e Distrito Federal no exercício 2017, de modo a evidenciar os entes que se destacaram tanto positiva, quanto negativamente e o correspondente potencial de melhoria.

\section{REFERENCIAL TEÓRICO}

Atualmente, a sociedade tem sido confrontada com um problema crescente: a majoração contínua dos índices de criminalidade. Em tal contexto, a adequação da destinação dos recursos públicos direcionados à área de segurança pública tem tido sua eficiência questionada (CARRETS; OLIVEIRA; MENEZES, 2018; WU et al., 2016; SCHULL; FEITÓSA; HEIN, 2014).

Ervilha e Lima (2019) defendem que o aumento da criminalidade e a necessidade de investimentos crescentes em segurança têm di- 
recionado a literatura econômica para a compreensão da complexidade da temática segurança pública. Isso porque a violência tem penalizado grande parte das economias em desenvolvimento, em especial a classe economicamente produtiva. E, para além das perdas humanas e de traumas físicos e psicológicos, a criminalidade está associada a altos custos econômicos, envolvendo gastos no tratamento de vítimas e na prevenção da violência, bem como perdas de investimentos, que deixam de ser captados em função da existência de crimes e do envolvimento de muitos indivíduos nos atos ilícitos.

Na mesma linha, Pinto e Coronel (2015) destacam que a criminalidade tem implicações econômicas, assim como sociais e políticas. Econômicas na medida em que a intensidade dos crimes impõe restrições a uma determinada localidade e que $\mathrm{o}$ ato em si pode estar relacionado à conjuntura da economia de um território; sociais em razão de implicar a qualidade de vida dos indivíduos e da sociedade; e, por fim, políticas, haja vista a necessidade de serem elaborados planos e estratégias a fim de combater tal fenômeno.

Adicionalmente, o crime está relacionado a diversos e diferentes fatores, como inflação, desemprego, taxa de juros, crescimento de favelas, baixa expectativa de ascensão social

Quadro 1 - Estudos sobre segurança pública

\begin{tabular}{|c|l|l|}
\hline Autores & \multicolumn{1}{|c|}{ Objetivo } & \multicolumn{1}{|c|}{ Principais conclusões } \\
$\begin{array}{c}\text { Ervilha e } \\
\text { Lima (2019) }\end{array}$ & $\begin{array}{l}\text { Analisar se as heterogeneidades } \\
\text { municipais em MG exercem influ- } \\
\text { ências nos indicadores de crimina- } \\
\text { lidade entre 2000 e 2014. }\end{array}$ & $\begin{array}{l}\text { As políticas de combate à criminalidade devem } \\
\text { ser conjugadas com outras políticas públicas } \\
\text { relacionadas à educação, assistência social, } \\
\text { considerando a faixa etária e a vulnerabilidade } \\
\text { socioeconômica da população. }\end{array}$ \\
\hline $\begin{array}{c}\text { Carrets, Oli- } \\
\text { veira e Mene- } \\
\text { zes (2018) }\end{array}$ & $\begin{array}{l}\text { Realizar uma análise espacial da } \\
\text { criminalidade do RS, identificando } \\
\text { padrões espaciais para os anos de }\end{array}$ & $\begin{array}{l}\text { Os resultados apontam para a existência de uma } \\
\text { maior dinâmica espacial nas ocorrências dos cri- } \\
\text { mes contra a pessoa do que para os crimes contra }\end{array}$ \\
\hline $\begin{array}{c}\text { Wakim e } \\
\text { Teixeira patrimônio. } \\
\text { (2018) }\end{array}$ & $\begin{array}{l}\text { Analisar a eficiência do Estatuto } \\
\text { do Desarmamento na redução } \\
\text { das mortes por arma de fogo nos }\end{array}$ & $\begin{array}{l}\text { O Estatuto do Desarmamento teve uma baixa } \\
\text { eficiência na redução das taxas de homicídios no }\end{array}$ \\
\hline estados brasileiros de 1996 a 2013. & uma vez que estas continuam a evidenciar \\
\hline
\end{tabular}

e do nível de eficiência nos gastos com educação (FERNANDES JUNIOR et al., 2017; SCHULL; FEITÓSA; HEIN, 2014; BECKER; HARTMANN; TAKEY 2017; ROMERO; MAGALONI; DÍAZ-CAYEROS, 2016). No Brasil, a questão está exacerbada a ponto de a criminalidade se sobrepor ao Estado, passando a ocupar e gerir territórios nas periferias e ultrapassar fronteiras internas e internacionais (GONÇALVES; SANTOS，2017; SOUSA; MATIAS; SEIXAS, 2015).

Scalco, Gomes e Carvalho (2007) apontam que o crescimento das taxas de criminalidade é marcado pela incapacidade de o Estado lidar com o problema da segurança pública. Perante essa realidade, reflete-se que tal inaptidão estatal advém da incapacidade de o Estado adotar políticas públicas eficientes para combater o crime, o qual advém de fatores alheios à presença do Estado ou se ambos estão relacionados.

Perscrutando os estudos empíricos preexistentes acerca da análise de políticas públicas de segurança pública, percebe-se que podem assumir diferentes perspectivas e abranger distintos espaços territoriais, violações ou grupo de vítimas, bem como abordar, tecnicamente, a eficiência de gastos em segurança. É o que demonstra o quadro 1. 


\begin{tabular}{|c|c|}
\hline $\begin{array}{l}\text { Santos, } \\
\text { Gontijo e } \\
\text { Amaral } \\
(2015)\end{array}$ & $\begin{array}{l}\text { Analisar os gastos estaduais em } \\
\text { segurança pública, observando } \\
\text { suas relações com as perspectivas } \\
\text { ideológicas dos partidos eleitos } \\
\text { para o Poder Executivo }\end{array}$ \\
\hline $\begin{array}{l}\text { Schull, } \\
\text { Feitósa e } \\
\text { Hein }(2014)\end{array}$ & $\begin{array}{l}\text { Medir a eficiência dos estados } \\
\text { brasileiros na utilização dos gastos } \\
\text { públicos na área de segurança. }\end{array}$ \\
\hline $\begin{array}{l}\text { Mello, Avelar } \\
\text { e Brito (2014) }\end{array}$ & $\begin{array}{l}\text { Apresentar uma análise crítica sobre } \\
\text { iniciativas de segurança pública } \\
\text { voltadas para a população LGBT. }\end{array}$ \\
\hline $\begin{array}{l}\text { Raimondo, } \\
\text { Labronici } \\
\text { e Larocca } \\
\text { (2013) }\end{array}$ & $\begin{array}{l}\text { Delinear o perfil da violência } \\
\text { perpetrada contra a mulher em um } \\
\text { município paranaense. }\end{array}$ \\
\hline $\begin{array}{l}\text { Peres et al. } \\
\text { (2012) }\end{array}$ & $\begin{array}{l}\text { Analisar a associação entre } \\
\text { homicídios e indicadores de } \\
\text { segurança pública no Município } \\
\text { de São Paulo, após controle para } \\
\text { taxa de desemprego e proporção de } \\
\text { jovens na população. }\end{array}$ \\
\hline $\begin{array}{l}\text { Carvalho e } \\
\text { Silva (2011) }\end{array}$ & $\begin{array}{l}\text { Discutir a política de segurança } \\
\text { pública adotada no Brasil contem- } \\
\text { porâneo }\end{array}$ \\
\hline $\begin{array}{l}\text { Pereira Filho, } \\
\text { Tannuri- } \\
\text { Pianto e } \\
\text { Sousa }(2010)\end{array}$ & $\begin{array}{l}\text { Calcular a relação entre custo e } \\
\text { eficiência na segurança pública dos } \\
\text { estados brasileiros. }\end{array}$ \\
\hline
\end{tabular}

Fonte: dados da pesquisa.

A criminalidade pode ser externada por diferentes violações a bens jurídicos distintos. Entre as que se destacam, podem ser considerados três distintos bens jurídicos tutelados pela lei, que são: a vida, o patrimônio e a dignidade sexual. Nessa linha, são enumerados os crimes de homicídio em sua modalidade dolosa, latrocínio e estupro.

Homicídio doloso é entendido como aquele em que o agente, efetivamente, teve a intenção de matar (RIBEIRO; COUTO, 2017;
Foi observada a variação positiva dos gastos quando os partidos são de esquerda e centro; e relativa aproximação dos percentuais de arrecadação investidos em segurança nos estados, independentemente dos partidos nos governos.

Dos 23 Estados analisados, 12 atingiram o nível máximo de eficiência, 2 apresentaram alto grau de eficiência, e os demais Estados atingiram médio grau de eficiência.

O balanço final aponta absoluto desequilíbrio entre a violência homofóbica e a atuação do governo brasileiro para mudar esse quadro.

Evidenciou-se que $93,4 \%$ das vítimas residiam na zona urbana; $82,8 \%$ tinham entre 20 e 59 anos; $54,2 \%$ viviam em união estável; $69,4 \%$ possuíam ensino fundamental; $52,7 \%$ desenvolviam atividade remunerada; $70,1 \%$ das violências ocorreram dentro de casa e as mais frequentes foram a psicológica e a física.

O papel das ações de segurança pública perde importância como fator explicativo para a redução nos níveis de homicídios, após controle para taxa de desemprego e redução na proporção de jovens.

Ocorreram avanços na democratização da política de segurança, por meio da maior participação da sociedade nas discussões e na implementação de ações nessa área.

Os índices de ineficiência são proporcionais à participação do mercado de drogas, à razão Polícia Militar/Polícia Civil, à taxa de abandono do ensino médio e à desigualdade de renda. Já as despesas com o Judiciário e o número de vagas no sistema penitenciário reduzem tais índices.

BRASIL, 1940). Enquadra-se na relação dos crimes contra a vida, pois o objetivo do autor do crime de homicídio doloso é, simplesmente, matar outrem (BECKER; HARTMANN; TAKEY, 2017).

Em outra frente, latrocínio é crime contra o patrimônio e significa matar alguém com o objetivo de subtrair coisa alheia móvel. Dizse, por conseguinte, que o agente mata outrem com o objetivo de roubar, pois, apenas com a morte da vítima, será possível que tenha a pos- 
se do bem almejado (BECKER; HARTMANN; TAKEY, 2017; BRASIL, 1940).

Ao fim, o crime de estupro é considerado uma das violências físicas e simbólicas com consequências mais danosas à vítima, uma vez que se refere ao vilipêndio do próprio corpo e dos valores atávicos fundamentais (CERQUEIRA; COELHO; FERREIRA, 2017). Inobstante a denominação remeta à antiga configuração do estupro apenas por meio da penetração vaginal não consentida, a legislação atual é bem mais ampla e define estupro como o ato de constranger alguém, homem ou mulher, mediante violência ou grave ameaça, a ter conjunção carnal ou a praticar ou permitir que, com ele, pratiquese ato libidinoso (BRASIL, 1940).

A abordagem da segurança também pode aprofundar-se no que concerne à avaliação de sua eficiência, ou seja, na razão entre os recursos empregados em segurança e a redução da criminalidade. A revisão de literatura encontrou estudos que relacionam investimentos com o retorno em taxas menores de criminalidade (BOUÇÃO et al., 2019; PEREIRA FILHO; TANNURI-PIANTO; SOUSA, 2010; SCHULL; FEITÓSA; HEIN, 2014). Abordando o tema, Afonso (2017) afirma que, no caso dos estados brasileiros, os gastos com segurança são elevados, o que demanda atenção sobre a qualidade do gasto. Tal problemática consiste em fator motivador adicional para o presente estudo sobre a eficiência de gastos com a segurança pública em nível estadual.

\section{PROCEDIMENTOS ME- TODOLÓGICOS}

Acerca das definições metodológicas do presente estudo, tem-se que, quanto aos objetivos ou fins, tem-se uma pesquisa descritiva, uma vez que se observam as características da segurança pública em diferentes estados brasileiros e no Distrito Federal no que se refere a seus índices de eficiência relativa. Sobre os meios ou procedimentos, trata-se de pesquisa documental, haja vista que os dados foram compilados de fonte documental preexistente, notadamente do Anuário de Segurança Pública 2018 (FÓRUM BRASILEIRO DE SEGURANÇA PÚBLICA, 2018), sendo coletados os dados pertinentes ao exercício 2017 por serem os mais modernos disponibilizados.

Com relação à abordagem do problema, o estudo assume um enfoque quantitativo, tendo em mente que serão mensurados os níveis de eficiência relativa das unidades com relação à segurança pública.

Para o cálculo do índice de eficiência relativa, foi utilizada a metodologia Análise Envoltória de Dados (do inglês Data Envelopment Analysis - DEA), a qual subsiste, precipuamente, em seus dois modelos clássicos: CCR ou CRS (Constant Returns to Scale) e BCC ou VRS (Variable Returns of Scale) (KAKIHARA; SILVA; POKER JUNIOR, 2016); o primeiro atua sobre um modelo de programação linear em retornos constantes de escala, e o segundo contempla retornos de escala variáveis (PESSANHA et al., 2013).

O DEA constitui-se em uma técnica de programação linear cujo objetivo é mensurar o desempenho de diferentes unidades tomadoras de decisão (Decision Making Units - DMU), quando a existência de múltiplas entradas e múltiplas saídas torne difícil a comparação (BOUÇÃO et al., 2019; MARIANO; ALMEIRA; REBELATTO, 2006; COELLI, 1996).

A aplicação do método DEA perpassa, necessariamente, por três etapas: (a) a identificação das DMUs; (b) a seleção das variáveis (inputs e outputs) relevantes e apropriadas ao estudo e; (c) a aplicação do modelo DEA adequado (BOUÇÃO et al., 2019; LINS; MEZA, 2000; FARIA; JANNUZZI; SILVA, 2008).

Nessa linha, quanto à identificação da DMUs, foi efetivada uma análise censitária sobre os estados brasileiros e Distrito Federal. Com relação às variáveis, utilizou-se apenas um input, que é o gasto per capita em segurança pública, posto ser a forma de investimento mais comum na política pública. Na extremidade oposta, foram utilizados três outputs que são quantidade de homicídios dolosos, de latrocínios e de estupros, todos por 100 mil habi- 
tantes. Além disso, como o aumento dos ditos índices levam à ineficiência do estado, utilizouse a razão oposta dos indicadores. Quanto ao modelo DEA, tendo em mente as peculiaridades de cada um dos modelos clássicos, entendeu-se que, para a presente pesquisa, seria mais adequada a aplicação do modelo VRS, com orientação output, isto é, visando maximizar os resultados com os mesmos insumos e com a premissa de retornos variáveis.

Por fim, para a análise envoltória de dados, foi utilizado o software Data Envelopment Analysis DEAP versão 2.1. Análises estatísticas descritivas, de frequência e correlações foram feitas com planilhas eletrônicas utilizando o Excel.

\section{ANÁLISE DOS RESULTADOS}

Por intermédio da Análise Envoltória de Dados, foi possível evidenciar os índices de eficiência relativa dos gastos públicos destinados à segurança pública no exercício 2017. De início, cabe observar que a média de eficiência das unidades componentes da amostra ficou em $65,6 \%$, o que já denota uma ampla margem para melhoria no desempenho das DMUs.

Os resultados de eficiência foram dispostos em ordem decrescente e classificados conforme o índice encontrado. No caso, adotou-se a classificação de Barros (2017) para os resultados de eficiência relativa com base no DEA. Tal opção decorreu da separação, em um grupo à parte, das unidades com $100 \%$ de eficiência, bem como das nomenclaturas mais intuitivas que são eficiência alta, média, baixa e muito baixa.

A tabela 1 aponta os resultados individuais das unidades em estudo, no que se refere a resultados de eficiência relativa, tipo de retorno de escala e benchmarcks.

Tabela 1 - Resultados de eficiência relativa, retorno de escala e benchmarcks

\begin{tabular}{|c|c|c|c|c|c|}
\hline Nível de eficiência & Rank & Estado & $\begin{array}{l}\text { \% eficiência } \\
\text { relativa }\end{array}$ & $\begin{array}{c}\text { Retorno de } \\
\text { escala }\end{array}$ & Benchmarcks \\
\hline \multirow{7}{*}{$\begin{array}{l}\text { Eficientes } \\
(a=100 \%)\end{array}$} & \multirow[t]{7}{*}{1} & Ceará & 100,0 & irs & - \\
\hline & & Maranhão & 100,0 & irs & - \\
\hline & & Minas Gerais & 100,0 & drs & - \\
\hline & & Paraíba & 100,0 & crs & - \\
\hline & & Piauí & 100,0 & irs & - \\
\hline & & Rio Grande do Norte & 100,0 & crs & - \\
\hline & & São Paulo & 100,0 & crs & - \\
\hline \multirow{2}{*}{$\begin{array}{l}\text { Eficiência Média } \\
(80 \%<\mathrm{a} \leq 99.9 \%)\end{array}$} & 8 & Paraná & 91,9 & drs & $\mathrm{MG}, \mathrm{SP}$ \\
\hline & 9 & Espírito Santo & 85,8 & drs & RN, SP, MG \\
\hline \multirow{7}{*}{$\begin{array}{c}\text { Eficiência Baixa } \\
(50 \%<\mathrm{a} \leq 80 \%)\end{array}$} & 10 & Bahia & 71,5 & crs & $\mathrm{RN}, \mathrm{PB}, \mathrm{SP}$ \\
\hline & 11 & Santa Catarina & 72,1 & drs & $\mathrm{SP}, \mathrm{MG}$ \\
\hline & 12 & Tocantins & 67,5 & drs & SP, MG \\
\hline & 13 & Mato Grosso do Sul & 65,5 & drs & SP, MG \\
\hline & 14 & Distrito Federal & 62,4 & drs & $\mathrm{PB}, \mathrm{MG}, \mathrm{SP}$ \\
\hline & 15 & Rio Grande do Sul & 56,2 & drs & $\mathrm{PB}, \mathrm{MG}, \mathrm{SP}$ \\
\hline & 16 & Amazonas & 50,7 & drs & MG, RN, SP \\
\hline
\end{tabular}




\begin{tabular}{c|c|l|c|c|c}
\hline \multirow{2}{*}{$\begin{array}{c}\text { Eficiência } \\
\text { Muito Baixa } \\
(\mathrm{a} \leq 50 \%)\end{array}$} & 17 & Rio de Janeiro & 48,2 & $\mathrm{drs}$ & $\mathrm{RN}, \mathrm{SP}, \mathrm{MG}$ \\
\cline { 2 - 6 } & 18 & Rondônia & 47,8 & $\mathrm{drs}$ & $\mathrm{SP}, \mathrm{MG}$ \\
\cline { 2 - 6 } & 19 & Sergipe & 47,2 & $\mathrm{drs}$ & $\mathrm{RN}, \mathrm{SP}, \mathrm{MG}$ \\
\hline & 20 & Roraima & 44,2 & $\mathrm{drs}$ & $\mathrm{RN}, \mathrm{SP}, \mathrm{MG}$ \\
\cline { 2 - 6 } & 21 & Goiás & 43,3 & $\mathrm{drs}$ & $\mathrm{RN}, \mathrm{SP}, \mathrm{MG}$ \\
\hline & 22 & Pernambuco & 41,9 & $\mathrm{crs}$ & $\mathrm{RN}, \mathrm{PB}, \mathrm{SP}$ \\
\hline & 23 & Mato Grosso & 40,8 & $\mathrm{drs}$ & $\mathrm{MG}, \mathrm{RN}, \mathrm{SP}$ \\
\hline & 24 & Alagoas & 38,3 & $\mathrm{drs}$ & $\mathrm{PB}, \mathrm{MG}, \mathrm{SP}$ \\
\hline & 25 & Acre & 34,0 & $\mathrm{drs}$ & $\mathrm{RN}, \mathrm{SP}, \mathrm{MG}$ \\
\hline & 26 & Amapá & 31,4 & $\mathrm{drs}$ & $\mathrm{MG}, \mathrm{RN}, \mathrm{SP}$ \\
\hline
\end{tabular}

Fonte: dados da pesquisa.

Os dados demonstraram a predominância de estados considerados com eficiência muito baixa, os quais corresponderam a $38,46 \%$ da amostra, ou 10 unidades. Em seguida, tem-se que sete estados $(26,92 \%$ da amostra) foram considerados eficientes. Ademais, seis estados foram considerados com eficiência baixa $(22,22 \%)$ e apenas dois com eficiência média $(7,41 \%)$.

É possível asseverar, portanto, que os resultados alcançados pela maioria das unidades estão abaixo do nível ótimo desejado, o que vai ao encontro da pesquisa Galdino, Guimarães e Carmo Filho (2015), com a qual converge também no que se refere à inclusão de Maranhão, Piauí e Rio Grande do Norte entre as unidades eficientes e Alagoas, Amapá e Mato Grosso ficaram entre as unidades menos eficientes.

Ademais, buscando compreender a relação entre os valores investidos e os índices de eficiência relativa, procedeu-se ao cálculo do coeficiente de correlação linear de Pearson (r). Tal teste consubstancia-se em estatística utilizada para medir a força, a intensidade ou o grau de relação linear entre duas variáveis aleatórias, propondo-se a ser uma medida de associação linear entre variáveis (LIRA; CHAVES NETO, 2006; SCHRIPPE et al., 2015; FIGUEIREDO FILHO; SILVA JUNIOR, 2009). Varia de $-1 \mathrm{a}+1$, sendo que o sinal (positivo ou negativo) indica a direção positiva ou negativa do relacionamento, enquanto o valor sugere a força da relação entre as variáveis (FIGUEIREDO FILHO; SILVA JUNIOR, 2009).
In casu, foi encontrado $\mathrm{r}=-0,533819$, o que denota que o desempenho apresentou associação negativa com o aumento do investimento. Desse modo, corrobora-se o estudo de Dantas et al. (2016), os quais concluíram que gastos em segurança pública superiores ou inferiores à média não terão, por implicação, melhoria ou piora nos níveis de eficiência.

Além do escore de eficiência técnica, a análise DEA disponibiliza escore de eficiência de escala, o qual pode possuir retorno constante (crs), crescente (irs) ou decrescentes (drs) (VECCHIA, 2014). A primeira, considerada ideal, é configurada quando aumento nos insumos gera proporcional aumento na produção, sem desperdícios. A segunda resta conformada quando o aumento dos insumos gera um aumento nos resultados maior que o proporcional. A terceira ocorre quando o aumento de resultados decorrente do aumento de insumos é menor que o proporcional (COELLI, 1996; VECCHIA, 2014).

Da tabela 1, denota-se que eficiência relativa não está necessariamente ligada a retornos constantes de escala, inobstante seja esse o cenário considerado ideal para a unidade. Tanto que apenas três das sete DMUs eficientes tiveram retornos constantes de escala, significando que, para tais unidades, insumos e produtos estão proporcionais, isto é, estão laborando em uma situação de máximo aproveitamento, sem desperdícios.

Entre as DMUs ineficientes, predomina o retorno decrescente de escala, o que sinali- 
za que, para o alcance de resultados positivos, deverá ser precedido de um desproporcional e maior incremento nos insumos que o desejado nos resultados. Para DMUs ineficientes, os retornos crescentes demonstram-se mais favoráveis, na medida em que resultados positivos são alcançados com um aumento menor que o proporcional nos insumos.

Por fim, o modelo DEA vincula como unidade de referência aquela DMU eficiente que possui características mais assemelhadas, quanto aos inputs e outputs, com relação à DMU ineficiente. Essa unidade de referência é denominada benchmark, e, com o fito de servir de modelo para que determinada unidade ineficiente melhore sua eficiência técnica, aponta o que deve ser modificado em inputs e outputs para transformar DMUs ineficientes em eficientes (CAVALCANTE; FARIA, 2009).

Quanto às unidades componentes da amostra, vê-se que, dos sete estados considerados eficientes, apenas quatro foram apontados como benchmarks para as DMUs ineficientes. São Paulo é a DMU mais vezes indicada como referência, aparecendo como benchmark para todas as 20 DMU's ineficientes. Em seguida, tem-se Minas Gerais, indicado como parâmetro para 18 unidades, Rio Grande do Norte, com 11 indicações e Paraíba, benchmarck para 6 DMUs.

Os inputs e outputs utilizados na presente investigação diferem dos utilizados nas pesquisas prévias, assim como os horizontes de tempo, dificultando a comparação entre pesquisas. São Paulo, por exemplo, aparece como eficiente na presente pesquisa, assim como na de Pereira Filho, Tannuri-Pianto e Sousa (2010), mas recebe escore baixo de eficiência na pesquisa de Schull, Feitósa e Hein (2014). Outro caso de discrepância é o do Ceará, que aparece como eficiente na presente pesquisa e na de Schull, Feitósa e Hein (2014), mas aparece como ineficiente na de Pereira Filho, Tannuri-Pianto e Sousa (2010). Os resultados apontam que há grandes discrepâncias nos níveis de eficiências entre os estados brasileiros e que a avaliação de eficiência deve levar em consideração diferentes ângulos de observação.

\section{CONSIDERAÇÕES FINAIS}

O presente estudo avaliou a eficiência dos gastos em segurança pública realizados pelos estados brasileiros e Distrito Federal no exercício 2017, tendo, por base, os valores investidos per capita e o inverso da taxa de homicídios dolosos, de latrocínios e de estupros por 100 mil habitantes.

Restou evidenciada uma eficiência média de $65,6 \%$, o que sinaliza que as unidades possuem margem para melhoria de seus resultados. No grupo das 27 DMUs analisadas, 10 tiveram eficiência muito baixa, sete foram consideradas eficientes, seis tiveram eficiência baixa e dois foram considerados com eficiência média.

Por meio do teste de correlação de Pearson, asseverou-se uma associação negativa existente entre eficiência relativa e aumento do investimento, sinalizando, conforme estudos pretéritos, que a elevação dos gastos, não necessariamente, gerará melhoria dos resultados, sendo necessária uma reflexão acerca da melhor forma de utilização dos recursos destinados às políticas de segurança pública.

Com relação aos retornos de escala, apenas três das sete DMUs eficientes - Paraíba, Rio Grande do Norte e São Paulo - tiveram retornos constantes, situação considerada ideal, uma vez que demonstra que a unidade está atuando sem desperdícios. No conjunto das unidades ineficientes, predominou o retorno decrescente de escala, significando que os insumos deverão ser desproporcionalmente superiores aos resultados pretendidos.

Dos sete estados eficientes, apenas quatro estados foram apontados como benchmarks para as DMUs ineficientes. São Paulo foi apontada como referência em todos os casos, ao passo que Minas Gerais é benchmarck para 18 unidades, Rio Grande do Norte para 11 DMUs, e Paraiba é benchmarck para 6 DMUs. Nessa linha, tem-se que as práticas utilizadas por São Paulo podem nortear a atividade dos estados ineficientes.

As fragilidades deste trabalho gravitam em torno das variáveis utilizadas para o alcance dos objetivos da pesquisa. A existência de pou- 
cos estudos relacionando gastos com segurança pública e índices de criminalidade não permite assegurar quais as melhores variáveis a serem utilizadas neste tipo de pesquisa. Nesse sentido, sugere-se que trabalhos futuros utilizem variáveis diversas na mensuração da eficiência dos gastos públicos em segurança pública, compondo modelos mais sofisticados. Outra possibilidade é a análise de eficiência com relação às políticas destinadas ao enfrentamento da violência em contextos específicos, como a violência doméstica contra a mulher, e aos crimes relacionados ao grupo LGBT.

\section{REFERÊNCIAS}

AFONSO, J. R. Gastos públicos com segurança pública. Revista Conjuntura Econômica, v. 71, n. 11, 2017.

BARROS, A. P. C. H. A eficiência relativa da governança eletrônica das universidades federais brasileiras. Dissertação (Mestrado em Administração e Controladoria) - Universidade Federal do Ceará, Fortaleza, 2017.

BECKER, A. C. V.; HARTMANN, E. S.; TAKEY, D. G. Distinção entre latrocínio e homicídio como crimes individuais. JICEX, v. 5, n. 5, 2017.

BOUÇÃO, G. M. et al. Relação entre Gastos Públicos, Educação e Criminalidade: uma Análise de Eficiência nos Estados Brasileiros. In: CONGRESSO USP DE INICIAÇÃO CIENTÍFICA EM CONTABILIDADE, 16., 2019, São Paulo. Anais [...]. São Paulo, 2019.

BRASIL. Constituição (1988). Constituição da República Federativa do Brasil de 1988. Brasília, DF: Presidência da república, 1988. Disponível em: http:/www.planalto.gov.br/ ccivil_03/constituicao/constituicaocompilado. htm. Acesso em: 18 fev. 2018.

BRASIL. Decreto-lei n ${ }^{\circ} 2.848$, de 7 de dezembro de 1940. Código Penal. Brasília, DF: Pre- sidência da república, 1940. Disponível em: http://www.planalto.gov.br/ccivil_03/Decreto -Lei/Del2848.htm. Acesso em: 18 fev. 2018.

BRASIL. Emenda Constitucional $\mathbf{n}^{0}$. 95, de 15 de dezembro de 2016. Altera o Ato das Disposições Constitucionais Transitórias, para instituir o Novo Regime Fiscal, e dá outras providências. Brasília, DF: Presidência da república, 2016. Disponível em: http://www.planalto. gov.br/ccivil_03/constituicao/emendas/emc/ emc95.htm. Acesso em: 18 fev. 2018.

CARRETS, F. D.; OLIVEIRA, J. de; MENEZES, G. R. A criminalidade no Rio Grande do Sul: uma análise espacial para anos de 2005, 2010 e 2015. Perspectiva Econômica, v. 14, n. $1,2018$.

CARVALHO, V. A. de; SILVA, M. R. F.. Política de segurança pública no Brasil: avanços, limites e desafios. Revista Katálysis, v. 14, n. $1,2011$.

CAVAlCANTE, G. T.; FARIA, R. C. O uso dos parâmetros de benchmarking da análise envoltória de dados (DEA) como instrumento de orçamentação. Revista Interdisciplinar Científica Aplicada, v. 3, n. 1, Sem I. 2009.

CERQUEIRA D.; COELHO D. S. C.; FERREIRA H. Estupro no Brasil: vítimas, autores, fatores situacionais e evolução das notificações no sistema de saúde entre 2011 e 2014 . Revista Brasileira de Segurança Pública, v. 11, n. 1, 2017.

CERQUEIRA, D. et al. Atlas da Violência 2018. Instituto de Pesquisa Econômica Aplicada (Ipea) e Fórum Brasileiro de Segurança Pública (FBSP). Rio de Janeiro: Ipea, 2018. Disponível em: http://www.ipea.gov.br/portal/ index.php?option $=$ com_content\&view $=$ article $\&$ id $=33410 \&$ Itemid $=432$. Acesso em: 13 fev. 2019.

COELLI, T. An Introduction to efficiency and 
productivity analysis. Massachusetts: Kluwer Academic Publishers, 1996.

DANTAS, F. C. et al. Eficiência nos gastos públicos em segurança dos estados do Nordeste. Revista Econômica do Nordeste, v. 47, n. 1, 2016.

ERVILHA, G. T.; LIMA, J. E. de. Um método econométrico na identificação dos determinantes da criminalidade municipal: a aplicação em Minas Gerais, Brasil (2000-2014). Economía, sociedad y territorio, v. 19 , n. 59 , p. 10591086, 2019.

FARIA, F. P.; JANNUZZI, P. M.; SILVA, S. J. Eficiência dos gastos municipais em saúde e educação: uma investigação através da análise envoltória no estado do Rio de Janeiro. Revista de Administração Pública, v. 42, n. 1, jan./fev. 2008 .

FERNANDES JUNIOR, L. et al. La criminalidade no Brasil: avaliação do impacto dos investimentos públicos e dos fatores socioeconômicos. Espacio Abierto, v. 26, n. 2, 2017.

FIGUEIREDO FILHO, D. B.; SILVA JÚNIOR, J. A. Desvendando os Mistérios do Coeficiente de Correlação de Pearson (r). Revista Política Hoje, v. 18, n. 1, 2009.

FÓRUM BRASILEIRO DE SEGURANÇA PÚBLICA. Anuário de Segurança Pública 2018. São Paulo, 2018.

GALDINO, J. A.; GUIMARÃES, M. G. V.; CARMO FILHO, M. M. do. Análise do desempenho na gestão das despesas orçamentárias com segurança pública no Brasil. Revista Ambiente Contábil, v. 7, n. 1, 2015.

GONÇALVES, R.; SANTOS, G. Rodas Culturais, UPP, Funk e Milícias: uma análise da cultura urbana carioca frente às políticas de segurança e às organizações criminosas. PragMATIZES-Revista Latino-Americana de
Estudos em Cultura, n. 12, 2017.

GONÇALVES, J. R.; SIQUEIRA, M. V. B. a segurança pública no Brasil. Revista Processus de Estudos de Gestão, Jurídicos e Financeiros, v. 10, n. 38, 2019.

INSTITUTO BRASILEIRO DE GEOGRAFIA E ESTATÍSTICA (IBGE). Estimativas da população 2017. Disponível em: https://www. ibge.gov.br/estatisticas-novoportal/sociais/ populacao/9103-estimativas-de-populacao.htmledicao $=16985 \& \mathrm{t}=$ resultados. Acesso em: 11 fev. 2018.

KAKIHARA, A. A. S. B. S.; SILVA, V. S. da; POKER JUNIOR, J. H. Análise da eficiência do gasto público em educação fundamental em oito diretorias de ensino de São Paulo. In: SIMPÓSIO BRASILEIRO DE PESQUISA OPERACIONAL, 48., 2016. Vitória. Anais [...]. Vitória: 2016.

LIMA, M.; MACIEL, S. L. Secondary Education reform in the Temer administration: corrosion of the right to education in the context of a financial crisis in Brazil. Revista Brasileira de Educação, v. 23, 2018.

LINS, M. P. E.; MEZA, L. A. Análise envoltória de dados e perspectivas de integração no ambiente do apoio à decisão. Rio de Janeiro: Coppe/ UFRJ, 2000.

LIRA, S. A.; CHAVES NETO, A. Coeficientes de correlação para variáveis ordinais e dicotômicas derivados do coeficiente linear de Pearson. Ciência \& Engenharia, v. 15, n. 1/2, 2006.

MARIANO, E. B.; ALMEIDA, M. R.; REBELATTO, D. N. Princípios Básicos para uma proposta de ensino sobre análise por envoltória de dados. In: CONGRESSO BRASILEIRO DE ENSINO DE ENGENHARIA (COBENGE 2006), 34., 2006, Passo Fundo, RS. Anais [...]. Passo Fundo, RS, 2006. Disponí- 
vel em https:/www.researchgate.net/profile/ Enzo_Mariano/publication/257409786_Principios_basicos_para_uma_proposta_de_ensino_sobre_analise_por_envoltoria_de_dados/ links/00463525379e8e2fbc000000.pdf. Acesso em: 13 abr. 2018.

MELLO, L.; AVELAR, R. B. de; BRITO, W. Políticas públicas de segurança para a população LGBT no Brasil. Estudos Feministas, 2014.

NORONHA, J. C. de et al. The future of the Brazilian Health System: a short review of its pathways towards an uncertain and discouraging horizon. Ciencia \& saude coletiva, v. 23, n. 6, 2018 .

OSDH. Observatório sírio dos direitos humanos, 2016. 2018. Disponível em: http:// www.syriahr.com/. Acesso em: 13 fev. 2019.

PEREIRA FILHO, O. A.; TANNURI-PIANTO, M. E.; SOUSA, M. da C. S. de. Medidas de custo-eficiência dos serviços subnacionais de segurança pública no Brasil: 2001-2006. Economia Aplicada, v. 14, n. 3, 2010.

PERES, M. F. T. et al. Evolução dos homicídios e indicadores de segurança pública no Município de São Paulo entre 1996 a 2008: um estudo ecológico de séries temporais. Ciência \& Saúde Coletiva, v. 17, 2012.

PESSANHA, J. F. M. et al. Implementando modelos DEA no R. X Simpósio de Excelência em Gestão de Tecnologia (SEGeT), v. 54, 2013.

PINTO, N. G. M.; CORONEL, D. A. A criminalidade no Brasil: uma análise das evidências empíricas. Revista Brasileira de Administração Científica, v. 6, n. 1, 2015.

RAIMONDO, M. L.; LABRONICI, L. M.; LAROCCA, L. M. Retrospecto de ocorrências de violência contra a mulher registradas em uma delegacia especial. Cogitare Enfermagem, v. 18, n. 1, 2013.

RIBEIRO, L. M. L.; COUTO, V. A. Tipos de homicídio e formas de processamento: existe relação?/Type of homicide and trial length: is there a relationship?. Revista Semestral do Departamento e do Programa de Pós-Graduação em Sociologia da UFSCar, v. 7, n. 2, 2017.

ROMERO, V.; MAGALONI, B.; DÍAZ-CAYEROS, A. Presidential Approval and Public Security in Mexico's War on Crime. Latin American Politics and Society, v. 58, n. 2, p. 100-123, 2016.

SANTOS, I. G. dos; GONTIJO, J. G. L.; AMARAL, E. F. L. A política de segurança pública no Brasil: uma análise dos gastos estaduais (19992010). Opinião Pública, v. 21, n. 1, 2015.

SCALCO, P. R.; GOMES, A. P.; CARVALHO, $H$. D. Criminalidade violenta em Minas Gerais: uma proposta de alocação de recursos em segurança pública. 2007. Tese (Doutorado) Master's thesis, Universidade Federal de Viçosa, 2007.

SCHULL, A. N.; FEITÓSA, C. G.; HEIN, A. F. Análise da eficiência dos gastos em segurança pública nos estados brasileiros através da análise envoltória de dados (DEA). Revista Capital Científico-Eletrônica, v. 12, n. 3, 2014.

SCHRIPPE, P. et al. Estratégia Empresarial para a Natura: Análise de Correlação e Previsão dos Lucros por Meio do Modelo Holt-Winters. Reuna, v. 20, n. 4, 2015.

SOUSA, F. Q.; MATIAS, D. de O. L.; SEIXAS, P. N. Estudo comparado acerca do crime organizado no Brasil e na Indonésia segundo o relatório periódico universal. Revista de Estudos Internacionais, v. 6, n. 2, 2015.

VECCHIA, D. D. Análise da eficiência das 
instituições de educação superior públicas da região nordeste do Brasil - 2008 a 2012. 2014. Dissertação (Mestrado em Economia) Universidade Federal da Bahia, Salvador, 2014.

WAKIM, V. R.; TEIXEIRA, E. C. Estatuto do Desarmamento no Brasil: uma análise sob a ótica da eficiência. Economic Analysis of Law Review, v. 9, n. 3, p. 83-106, 2018.

WU, S. et al. SAPE: A system for situation-aware public security evaluation. In: AAAI CONFERENCE ON ARTIFICIAL INTELLIGENCE, 30., 2016, Arizona, USA. Anais [...]. Arizona, USA, 2016. 